\title{
Clinical impact of endocapillary proliferation according to the Oxford classification among adults with Henoch- Schönlein purpura nephritis: a multicenter retrospective cohort study
}

Koji Inagaki ${ }^{1}$, Ahmad Baseer Kaihan', Asaka Hachiya', Takaya Ozeki ${ }^{1}$, Masahiko Ando², Sawako Kato', Yoshinari Yasuda ${ }^{1}$ and Shoichi Maruyama ${ }^{1 *}$ (D)

\begin{abstract}
Background: Henoch-Schönlein purpura nephritis (HSPN) is a form of small vessel vasculitis associated with purpura and IgA deposition in the glomeruli. The International Study of Kidney Disease in Children (ISKDC) classification predicts renal prognosis in children with HSPN, but not in adults. Additionally, it is not well known whether the Oxford classification 2016 and/or the Japanese Histologic classification (JHC) are associated with renal outcome. Herein, we investigated the relationship between pathological characteristics and renal outcome among adult patients with HSPN.
\end{abstract}

Methods: A multicenter retrospective cohort study was conducted in adult patients with HSPN who underwent renal biopsy between 2004 and 2014. Two nephrologists classified each patient according to the Oxford classification 2016, JHC, and the ISKDC classification. Renal outcome was defined by a 30\% decline in the eGFR and/or end-stage kidney disease.

Results: We enrolled 74 adult patients with HSPN (mean age, $47.8 \pm 17.4$ years; mean eGFR, $76.4 \pm 25.8 \mathrm{ml} / \mathrm{min} / 1$. $73 \mathrm{~m}^{2}$; median proteinuria, 1.40 [IQR: 0.70-2.38] g/day). During a mean follow-up period of $68.0 \pm 33.0$ months, fourteen patients (18.9\%) reached the renal outcome, and all 14 had received immunosuppressive therapy. The logrank test revealed that event-free renal survival was significantly shorter in patients with endocapillary proliferation (E1) according to the Oxford classification than in those with EO ( $p=0.0072)$. However, the JHC, ISKDC classification and other Oxford lesions could not demonstrate a significant difference in event-free renal survival. In a multivariate Cox model adjusted for clinical and pathological factors, age $(H R, 1.57 ; 95 \% \mathrm{Cl}, 1.12-2.21)$ and $\mathrm{E}$ lesion $(\mathrm{HR}, 6.71$; 95\% Cl, 1.06-42.7) were independent risk factors for renal outcome.

Conclusions: Endocapillary proliferation is significantly associated with renal outcome in adult patients with HSPN, including those receiving immunosuppressive therapy. Other Oxford classification lesions, JHC, and ISKDC classification were not associated with renal outcome.

Keywords: Adult, HSPN, Oxford classification, Endocapillary proliferation, JHC

\footnotetext{
* Correspondence: marus@med.nagoya-u.ac.jp

'Department of Nephrology, Nagoya University Graduate School of

Medicine, 65 Tsurumai-cho, Showa-ku, Nagoya 466-8550, Japan

Full list of author information is available at the end of the article
}

(c) The Author(s). 2018 Open Access This article is distributed under the terms of the Creative Commons Attribution 4.0 International License (http://creativecommons.org/licenses/by/4.0/), which permits unrestricted use, distribution, and reproduction in any medium, provided you give appropriate credit to the original author(s) and the source, provide a link to the Creative Commons license, and indicate if changes were made. The Creative Commons Public Domain Dedication waiver (http://creativecommons.org/publicdomain/zero/1.0/) applies to the data made available in this article, unless otherwise stated. 


\section{Background}

Henoch-Schönlein purpura (HSP) is a form of small vessel vasculitis. According to the European League Against Rheumatism/Pediatric Rheumatology International Trials Organization/Pediatric Rheumatology European Society (EULAR/PRINTO/PRES) classification criteria, the diagnoses of HSP confirmed by the presence of purpura and one of the following manifestations: abdominal pain, arthralgia, renal insufficiency, and leukocytoclastic vasculitis with predominant IgA deposits [1]. About $70-80 \%$ of adult patients with HSP develop nephritis (HSPN) manifesting as proteinuria, hematuria, or renal insufficiency $[2,3]$. Although, the clinical features of HSPN are different from those of IgA nephropathy (IgAN), the histological and immunofluorescence findings of the two diseases are indistinguishable. Additionally, the glycosylated IgA1 is elevated in both IgAN and HSPN [4]. Thus, it is believed that HSPN and IgAN have common pathogenic mechanisms.

The incidences of IgAN and HSPN are higher among Asian people. In the UK, the annual incidence rates of HSP among black people were lower than those among Asian people [5]. In multinational research, IgAN and HSPN are more common in Asia and Europe, while less common in the USA and Latin America among biopsyproven kidney diseases [6]. In China, HSPN was the second-most frequently identified disease among biopsyproven secondary glomerular diseases [7]. Additionally, the length of hospital stay was longer among Asian people than among Caucasians [8]. Thus, HSPN is more common and severe disease among Asians in comparison to other populations.

The renal prognosis of HSPN in adults is worse than that in children [9], and approximately $10 \%$ of adults with HSPN reach end-stage kidney disease (ESKD) within 15 years [10]. Clinical findings identified as risk factors for chronic kidney disease (CKD) include old age, impairment of renal function, and massive proteinuria at the time of HSPN diagnosis [3, 9, 10]. According to the International Study of Kidney Disease in Children (ISKDC) classification, the degree of crescent formation predicts renal prognosis [11]. Although, ISKDC classification is associated with renal prognosis in children with HSPN [12], the same association was not observed in adults with HSPN $[9,13]$.

In 2009, a working group of the International IgAN Network and the Renal Pathology Society developed the Oxford classification to predict the renal prognosis in IgAN patients based on pathological findings $[14,15]$. This team identified four histopathologic features associated with renal outcomes independent of clinical parameters: mesangial hypercellularity $(\mathrm{M})$, endocapillary proliferation (E), segmental sclerosis/adhesion (S), and tubular atrophy/interstitial fibrosis (T). Additionally, cellular or fibrocellular crescents $(C)$ were added to the Oxford classification in 2016 [16]. In 2013, the Japanese Histologic classification (JHC) was reported to predict the progression to ESKD in patients with IgAN in Japan [17]. Histologic grades (HGs) in the JHC are based on glomerular lesions which consist of cellular crescent, fibrocellular crescent, fibrous crescent, segmental sclerosis, and global sclerosis. HG I, HG II, HG III and HG IV correspond to < $25 \%, 25-49 \%, 50-74 \%$, and $\geq 75 \%$ of glomeruli, respectively. JHC was validated for the prediction of renal prognosis in patients with IgAN in 2015 [18, 19].

Only one previous study examined the application of the Oxford classification 2009 in adults with HSPN. Kim et al. reported that Oxford $\mathrm{E}$ and $\mathrm{T}$ lesions predicted a renal prognosis of $\geq 30 \%$ decline in eGFR or ESKD in 61 adults with HSPN [13]. However there has been no study that validated the HSPN pathology. Additionally, it is unclear whether the Oxford C lesion or JHC is associated with poor renal outcome.

Therefore, we investigated the relationship between pathological characteristics and renal outcome among adult HSPN patients.

\section{Methods}

\section{Study design and subjects}

We performed a retrospective cohort study of adults ( $\geq 18$ years) with HSPN who underwent a renal biopsy between 2004 and 2014 at fourteen different medical centers (Nagoya University Hospital, Japanese Red Cross Nagoya Daiichi Hospital, Kasugai Municipal Hospital, Anjo Kosei Hospital, Konan Kosei Hospital, Toyota Kosei Hospital, Ichinomiya Municipal Hospital, Handa City Hospital, Toyohashi Municipal Hospital, Yokkaichi Municipal Hospital, Ogaki Municipal Hospital, Chutoen General Medical Center, Gifu Prefectural Tajimi Hospital, and Nagoya Memorial Hospital). We included patients diagnosed with HSPN according to the EULAR/ PRINTO/PRES HSP criteria [1] and the presence of IgA-dominant immune deposits on renal biopsy [9]. We excluded patients with less than 12 months of follow-up or with renal biopsy specimens with fewer than eight glomeruli. Patients were followed up until June 2018. During the study period, 89 patients with HSPN underwent a renal biopsy. We excluded ten patients followed up for less than 12 months and five patients with fewer than eight glomeruli in renal biopsy specimens. Seventyfour patients were analyzed.

\section{Clinical parameters}

We analyzed the clinical parameters from the medical records obtained when the patients underwent renal biopsy. A diagnosis of hypertension was defined as blood pressure (BP) values $\geq 140 / 90 \mathrm{mmHg}$ or a prescription of antihypertensive drugs. A diagnosis of diabetes was defined 
as HbA1c levels $\geq 6.5 \%$ or treatment with antidiabetics medications. We calculated the estimated glomerular filtration rate (eGFR) using the modified equation for Japanese $\left[\mathrm{eGFR}=194 \times \mathrm{sCr}^{-1.094} \times \mathrm{age}^{-0.287} \times 0.739\right.$ (if female) $][20]$.

\section{Histological parameters}

We stained the renal biopsy samples by periodic acidSchiff and Masson's trichrome. Two nephrologists (K.I and AB.K) evaluated the renal biopsy specimens. Each histologic lesion was graded according to the ISKDC Classification, Oxford classification 2016, and JHC [16, 17].

The Oxford classification 2016 is based on the MEST-C score. M0 indicates the involvement of $\leq 50 \%$ of glomeruli with $\geq 4$ cells/mesangial area and M1 indicates the involvement of $\geq 50 \%$ of glomeruli with $\geq 4$ cells/mesangial area. E0 and E1 indicate the absence and presence of endocapillary proliferation, respectively, and S0 and S1 refer to the absence and presence of segmental glomerulosclerosis or tuft adhesion, respectively. T0, $\mathrm{T} 1$ and T2 indicate the degree of tubular atrophy or interstitial fibrosis in $\leq 25 \%, 26-50 \%$, and $>50 \%$ of the cortical area, respectively [14]. C0, C1 and C2 refer to the amount of cellular or fibrocellular crescents of glomeruli as absent, $\leq 25 \%$, and $>25 \%$, respectively [21].

The ISKDC classification is used to analyze the degree of crescent formation. It includes six histological grades: grade I, minimal glomerular abnormalities without crescents; grade II, mesangial proliferation without crescents; grade III, mesangial proliferation with crescents in $<50 \%$ of glomeruli; grade IV, mesangial proliferation with crescents in $50-75 \%$ of glomeruli; grade $\mathrm{V}$, mesangial proliferation with crescents in $>75 \%$ of glomeruli; and grade VI, membranoproliferative-like lesions [11].

The JHC is based on glomerular lesions in kidney biopsy samples. It includes four HGs, that reflect $<25 \%$, $25-49 \%, 50-74 \%$, and $\geq 75 \%$ of glomeruli. Histologically, the glomerular lesions are seen as follows; cellular crescent, fibrocellular crescent, fibrous crescent, segmental sclerosis, and global sclerosis [17].

\section{Study outcomes}

The primary outcome of this study was a $30 \%$ decline in the eGFR from the baseline and/or ESKD.

\section{Statistical analyses}

Parametric and nonparametric variables were expressed as means \pm standard deviations (SD) and medians and interquartile ranges (IQRs). They were compared using Student's t-test and the Mann-Whitney $U$ test. Categorical variables were expressed in percentages and were compared using the Fisher's exact test. The Spearman correlation coefficient was used to determine the relationship between two histologic lesions. Kaplan-Meier survival curves were used to analyze freedom from the primary outcome in patients grouped according to the following classification: $\mathrm{M} 0 / 1, \mathrm{E} 0 / 1, \mathrm{~S} 0 / 1, \mathrm{~T} 0 / 1+2, \mathrm{C} 0 /$ $1 / 2$, ISKDC (grade I + II/III + IV), and JHC (HG I/II + III + IV). We used the univariate Cox regression to determine the factors predicting the primary outcome. Proteinuria was measured using time-collection urine, but we were not able to measure time-collection urine in four patients. Thus, they were assessed by calculating the spot urine protein-creatinine ratio. Variables with $P$ values $<0.30$ in the univariate analysis were examined in the multivariate analysis. These results were expressed as hazard ratios (HRs) with 95\% confidence intervals (CIs). P values $<0.05$ were considered statistically significant. All statistical analyses were performed with EZR (Saitama Medical Center, Jichi Medical University, Saitama, Japan). EZR is a graphical user interface for R statistics (The $\mathrm{R}$ Foundation for Statistical Computing, Vienna, Austria) [22].

\section{Results \\ Baseline clinical and pathological characteristics}

The baseline clinical characteristics are shown in Table 1. The mean age was $47.8 \pm 17.4$ years, and $47.3 \%$ were male (the detailed data were shown in Additional file 1). The mean eGFR was $76.4 \pm 25.8 \mathrm{~mL} / \mathrm{min} / 1.73 \mathrm{~m}^{2}$, and the median proteinuria was 1.40 [IQR: $0.70-2.38$ ] g/day. The median duration between lower limb purpura and the time of renal biopsy was 53 [IQR: 25-168] days. After a median kidney biopsy procedure period of 12 [IQR: 1-25] days, oral prednisolone (PSL) was prescribed to $61(82.4 \%)$ patients.

Histologic characteristics are also shown in Table 1. Findings consistent with M1, E1, and S1 were observed in $5(6.8 \%), 38(51.4 \%)$, and $38(51.4 \%)$ patients, respectively. In patients with E1, the median number of glomeruli with endocapillary proliferation was $14.3 \%$ [IQR: 8.03-22.4]. Findings consistent with T1 and T2 were observed in $14(18.9 \%)$ and $4(5.4 \%)$ patients, respectively. Crescents (ISKDC grade III + IV + V) were identified in $54(73.0 \%)$ patients, including two (3.7\%) with crescents in $\geq 50 \%$ of glomeruli (ISKDC grade IV $+V$ ). Findings consistent with $\mathrm{C} 1$ and $\mathrm{C} 2$ were found in 35 (47.3\%) and 17 (23.0\%) patients, respectively. HG I, II, and III in the $\mathrm{JHC}$ were diagnosed in 39 (52.7\%), 27 (36.5\%), and 8 (10.8\%) patients, respectively.

Table 2 presents correlations between the different histologic variables. The strongest correlation was found between the Oxford C lesion and ISKDC classification $(r=0.81)$. Moreover, JHC strongly correlated with Oxford $\mathrm{T}(r=0.56)$ and $C(r=0.62)$ and ISKDC classification $(r=0.55)$.

Table 3 shows a comparison of the clinical features by three pathological classifications. Oxford $M$ is not shown because there were very few M1 lesions. There were significant age-related differences in Oxford $\mathrm{T}$ and $\mathrm{C}$ 
Table 1 Baseline clinical and pathological characteristics in 74 adults with HSPN

\begin{tabular}{|c|c|}
\hline & All $(n=74)$ \\
\hline \multicolumn{2}{|l|}{ Clinical parameters } \\
\hline Age, years & $47.8 \pm 17.4$ \\
\hline Male/female & $35(47.3) / 39(52.7)$ \\
\hline Body mass index, $\mathrm{kg} / \mathrm{m}^{2}$ & $23.3 \pm 4.41$ \\
\hline Diabetes & $7(9.5)$ \\
\hline Hypertension & $26(35.1)$ \\
\hline Systolic blood pressure, mmHg & $125.7 \pm 16.9$ \\
\hline $\begin{array}{l}\text { Diastolic blood pressure, } \\
\mathrm{mmHg}\end{array}$ & $74.1 \pm 12.2$ \\
\hline Gross hematuria & $13(17.6)$ \\
\hline Abdominal symptoms & $25(33.8)$ \\
\hline Arthralgia & $18(24.3)$ \\
\hline $\mathrm{eGFR}, \mathrm{mL} / \mathrm{min} / 1.73 \mathrm{~m}^{2}$ & $76.4 \pm 25.8$ \\
\hline Total cholesterol, mg/dL & $216.4 \pm 62.4$ \\
\hline Serum uric acid, mg/dL & $5.3[4.1-7.1]$ \\
\hline Serum $\lg A, \mathrm{mg} / \mathrm{dL}$ & 333 [258-453] \\
\hline IgA/C3 ratio & $3.01[2.18-3.76]$ \\
\hline Proteinuria, g/day & $1.40[0.70-2.38]$ \\
\hline Proteinuria, $\mathrm{g} / \mathrm{gCr}$ & $1.87[1.09-3.32]$ \\
\hline $\mathrm{U}-\mathrm{RBC} \geq 30 / \mathrm{HPF}$ & $38(51.4)$ \\
\hline $\begin{array}{l}\text { Days between purpura onset } \\
\text { and renal biopsy }\end{array}$ & $53[25-168]$ \\
\hline \multicolumn{2}{|l|}{ Pathological parameters } \\
\hline Oxford M0/M1 lesion & $69(93.2) / 5(6.8)$ \\
\hline Oxford E0/E1 lesion & $36(48.6) / 38(51.4)$ \\
\hline Oxford S0/S1 lesion & $36(48.6) / 38(51.4)$ \\
\hline Oxford T0/1/2 lesion & $56(75.7) / 14(18.9) / 4(5.4)$ \\
\hline Oxford C0/1/2 lesion & $22(29.7) / 35(47.3) / 17(23.0)$ \\
\hline$J \mathrm{HC}$ I/II/III/IV & $39(52.7) / 27(36.5) / 8(10.8) / 0(0)$ \\
\hline ISKDC grade I/II/III/IVN & $6(8.1) / 14(18.9) / 52(70.3) / 2(2.7) / 0(0)$ \\
\hline \multicolumn{2}{|l|}{ Treatment } \\
\hline RASB & $56(75.7)$ \\
\hline $\begin{array}{l}\text { Days between renal } \\
\text { biopsy and steroid therapy }\end{array}$ & $12[1-25]$ \\
\hline Oral PSL & $61(82.4)$ \\
\hline mPSL therapy & $47(63.5)$ \\
\hline
\end{tabular}

Values are presented as the mean ( $\pm \mathrm{SD})$, the median [IQR], and numbers (\%) HSPN Henoch- Schönlein purpura nephritis, eGFR estimated glomerular filtration rate, U-RBC urinary red blood cell sediments, HPF high power field, $M$ mesangial hypercellularity, $E$ endocapillary proliferation, $S$ segmental sclerosis/ adhesion, $T$ tubular atrophy/interstitial fibrosis, $C$ cellular or fibrocellular crescents, JHC Japanese histologic classification, ISKDC International Study of Kidney Disease in Children, RASB renin-angiotensin system blockers, PSL prednisolone, $M P S L$ methylprednisolone lesions, and JHC. eGFR varied significantly by $\mathrm{T}$ lesion, JHC, and ISKDC classification. Proteinuria varied significantly by Oxford $\mathrm{E}$ and $\mathrm{C}$ lesions, and ISKDC classification.

\section{Renal outcome study}

During a mean follow-up period of $68.0 \pm 33.0$ months, fourteen patients (18.9\%) reached the renal outcome, defined by a $30 \%$ decline in eGFR from the baseline. Among them, only one patient developed ESKD after 11 years following the kidney biopsy. All patients who showed $\mathrm{a} \geq 30 \%$ decline in eGFR had received oral PSL. Kaplan-Meier survival curves are shown in Fig. 1. The log-rank test revealed significant between-group differences in event-free renal survival in patients with $\mathrm{E} 0$ and E1 lesions $(p=0.0072)$. The $\mathrm{M}, \mathrm{S}, \mathrm{T}$, and $\mathrm{C}$ lesions, ISKDC classification, and JHC did not show a significant association with renal outcome. In univariate Cox regression analysis, Oxford E lesion (HR: 6.13, 95\% CI: 1.36-27.7) and patient age (HR: 1.64, 95\% CI: 1.17-2.30) were significantly associated with renal outcome (Table 4). Male sex and $C$ lesion showed tendencies of association with poor renal outcome, but these tendencies were not statistically significant. Table 4 presents multivariate models adjusted for clinical and pathological factors. In model 1, Oxford E lesion (HR: 8.94, 95\% CI: 1.44-55.7) and patient age (HR: $1.58,95 \%$ CI: 1.15-2.18) were significantly associated with an increased risk of poor renal outcome after adjustment for clinical factors (age, sex, and proteinuria). $\mathrm{S}$ lesion, $\mathrm{T}$ lesion, $\mathrm{C}$ lesion, ISKDC classification, and JHC were not associated with an increased risk of poor renal outcome after adjustment for clinical factors. In model 2, Oxford E lesion (HR: 6.71, 95\% CI: 1.06-42.7) and patient age (HR: 1.57, 95\% CI: 1.12-2.21) were significantly associated with an increased risk of poor renal outcome after adjusting for clinical factors, $\mathrm{T}$ lesion, and $\mathrm{C}$ lesion.

\section{Discussion}

In this study, we retrospectively evaluated renal pathological severity in 74 consecutive patients with HSPN at fourteen different hospitals according to the ISKDC classification, Oxford classification 2016, and JHC. In the Oxford classification 2016, E lesion was significantly associated with an increased risk of poor renal outcome, but the other Oxford lesions including $\mathrm{C}$ lesion were not. The JHC and ISKDC classification were not associated with renal outcome in our study. To our knowledge, this is the first report that simultaneously analyzes the Oxford classification 2016, JHC, and the ISKDC classification for their association with renal outcome in adults with HSPN.

One study evaluated adult HSPN pathology according to the Oxford classification 2009. Kim et al. reported 
Table 2 Spearman correlations between histologic variables in 74 adults with HSPN

\begin{tabular}{|c|c|c|c|c|c|c|}
\hline & $E$ & $\mathrm{~S}$ & $T$ & $C$ & $\mathrm{JHC}$ & ISKDC \\
\hline$M$ & $-0.28(p=0.017)$ & $-0.061(p=0.61)$ & $-0.034(p=0.78)$ & $-0.28(p=0.017)$ & $-0.15(p=0.19)$ & $-0.27(p=0.019$ \\
\hline E & & $0.026(p=0.82)$ & $-0.046(p=0.70)$ & $0.40(p<0.001)$ & $0.11(p=0.34)$ & $0.40(p<0.001)$ \\
\hline S & & & $0.12(p=0.32)$ & $0.17(p=0.14)$ & $0.21(p=0.069)$ & $0.23(p=0.050)$ \\
\hline $\mathrm{T}$ & & & & $0.098(p=0.41)$ & $0.56(p<0.001)$ & $0.26(p=0.027)$ \\
\hline C & & & & & $0.62(p<0.001)$ & $0.81(p<0.001)$ \\
\hline $\mathrm{JHC}$ & & & & & & $0.55(P<0.001)$ \\
\hline
\end{tabular}

HSPN Henoch- Schönlein purpura nephritis, $M$ mesangial hypercellularity, $E$ endocapillary proliferation, $S$ segmental sclerosis/adhesion, $T$ tubular atrophy/interstitial fibrosis, C cellular or fibrocellular crescents, JHC Japanese histologic classification, ISKDC International Study of Kidney Disease in Children

that $\mathrm{E}$ and $\mathrm{T}$ lesions were significantly associated with poor renal outcome in 61 adults with HSPN during a median follow-up period of 49.3 months [13]. Our study also showed that E lesion had an unfavorable influence on renal survival, even in patients with HSPN receiving immunosuppressive therapy. On the other hand, E lesion was associated with poor renal prognosis in IgAN patients with no immunosuppressive therapy [14, 23], but not in those receiving immunosuppressive therapy [14]. These reports indicate that HSPN patients with an E1 lesion are more resistant to immunosuppressive therapy than IgAN patients with an E1 lesion. However, the rates of glomerular lesions with endocapillary proliferation were almost the same in patients with IgAN and those with HSPN. In IgAN patients with an E1 lesion, the median number of glomeruli with endocapillary proliferation was $12 \%$ [14]. In our study, in HSPN patients with an E1 lesion, the median number of glomeruli with endocapillary proliferation was $14 \%$. Thus, the characteristics of endocapillary proliferation might have been different between IgAN and HSPN, rather than the number of glomeruli with endocapillary proliferation.
Therefore, further studies are needed to determine the mechanism of endocapillary proliferation in HSPN.

In our study, tubular atrophy and interstitial fibrosis were not associated with renal outcome. However, in the HSPN study by Kim et al., T lesion was an independent risk factor for renal outcome. In addition, many studies have shown the utility of Oxford $\mathrm{T}$ lesions for predicting the renal outcome in patients with IgAN $[14,19,24,25]$. We hypothesize that this discrepancy in results was due to aging. HSPN patients with T1 and T2 lesions were significantly older than those with a T0 lesion in our study. Furthermore, the patients we registered were older than those enrolled in the study by Kim et al. (mean age, $47.8 \pm 17.4$ vs. $34.1 \pm 16.4$, respectively). Thus, $\mathrm{T}$ lesions may not have been related to HSPN severity but may have been associated with arteriosclerosis.

As in a previous study, our study also showed that ISKDC classification was not associated with poor renal outcome $[9,13]$. More than $90 \%$ of our patients with crescent formation were classified as ISKDC classification grade III (crescents in $<50 \%$ of glomeruli) which is consistent with the findings of a previous study [9].

Table 3 Comparison of clinical features according to three pathological classifications in 74 adults with HSPN

\begin{tabular}{|c|c|c|c|c|c|c|}
\hline Factor & Age (years) & $P$ values & eGFR $\left(\mathrm{mL} / \mathrm{min} / 1.73 \mathrm{~m}^{2}\right)$ & $P$ values & Proteinuria (g/day) & $P$ values \\
\hline EO & $47.4 \pm 18.0$ & 0.85 & $77.1 \pm 29.2$ & 0.83 & $0.77[0.48-1.32]$ & $<0.001$ \\
\hline E1 & $48.2 \pm 17.0$ & & $75.7 \pm 22.4$ & & $1.83[1.40-4.58]$ & \\
\hline so & $46.9 \pm 18.1$ & 0.65 & $77.2 \pm 26.6$ & 0.80 & $1.38[0.78-2.44]$ & 0.74 \\
\hline S1 & $48.7 \pm 16.8$ & & $75.6 \pm 25.4$ & & $1.41[0.64-2.25]$ & \\
\hline T0 & $45.6 \pm 17.3$ & 0.048 & $82.5 \pm 23.5$ & $<0.001$ & $1.41[0.63-2.32]$ & 0.69 \\
\hline $\mathrm{T} 1$ or 2 & $54.8 \pm 16.3$ & & $57.3 \pm 23.7$ & & $1.29[0.74-2.44]$ & \\
\hline $\mathrm{CO}$ & $44.6 \pm 19.6$ & 0.016 & $84.5 \pm 30.1$ & 0.098 & $0.60[0.44-1.07]$ & $<0.001$ \\
\hline C1 & $44.7 \pm 15.9$ & & $76.1 \pm 23.5$ & & 1.50 [0.99-2.04] & \\
\hline$C 2$ & $58.3 \pm 13.7$ & & $66.6 \pm 21.9$ & & 2.30 [1.70-4.89] & \\
\hline $\mathrm{JHCl}$ & $42.5 \pm 17.7$ & 0.005 & $85.5 \pm 24.8$ & $<0.001$ & $1.10[0.57-1.84]$ & 0.10 \\
\hline JHC II or III & $53.7 \pm 15.2$ & & $66.2 \pm 23.2$ & & $1.70[0.96-2.55]$ & \\
\hline ISKDC I or II & $43.8 \pm 20.2$ & 0.22 & $87.7 \pm 28.5$ & 0.020 & $0.67[0.45-1.12]$ & 0.0052 \\
\hline ISKDC III or IV & $49.3 \pm 16.2$ & & $72.2 \pm 23.6$ & & 1.70 [0.98-2.49] & \\
\hline
\end{tabular}



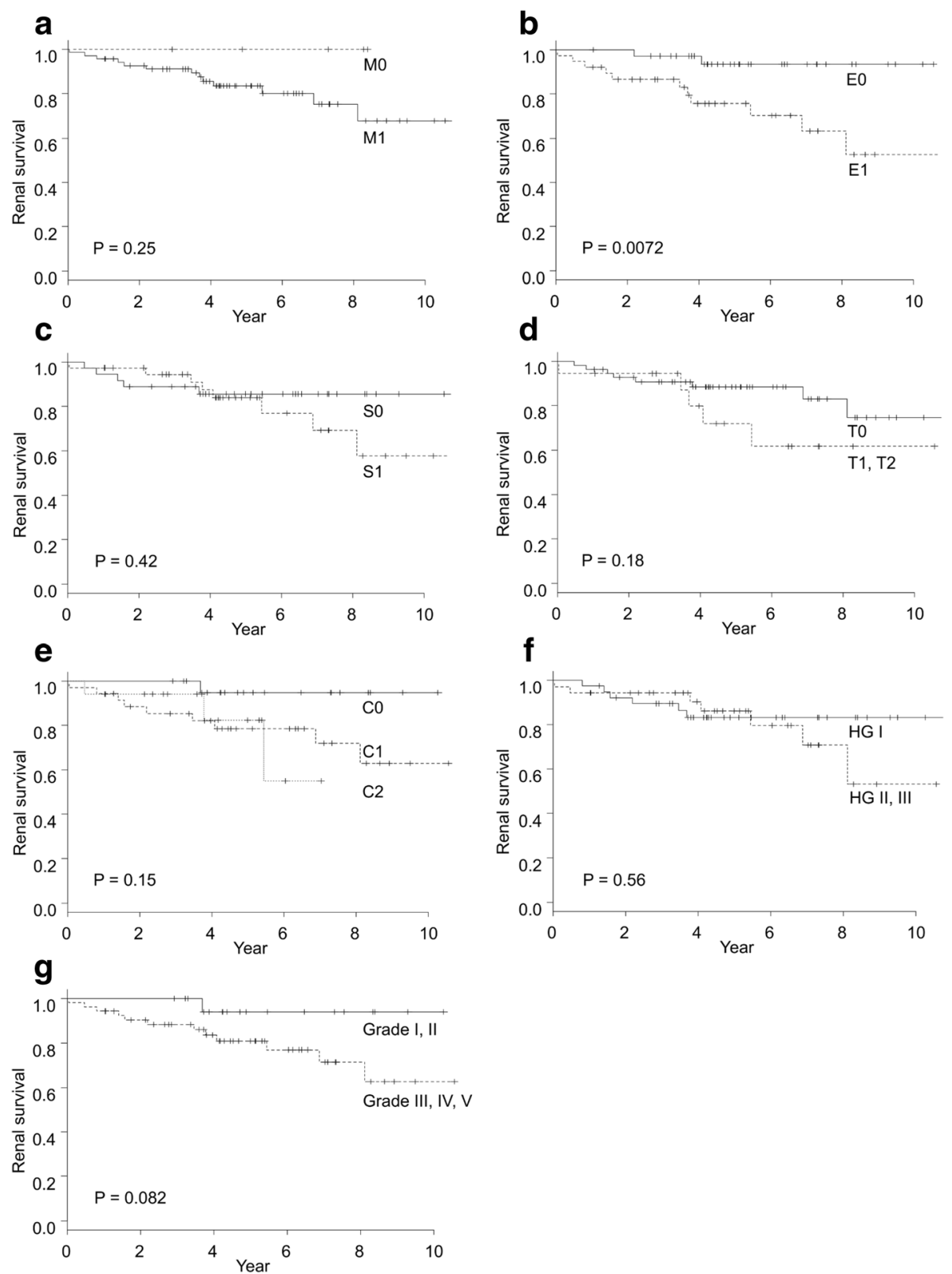

Fig. 1 Kaplan-Meier survival curve analyses of event-free renal survival by each pathological classification. a Mesangial hypercellularity (M0 vs. M1). b Endocapillary proliferation (EO vs. E1). c Segmental sclerosis/adhesion (SO vs. S1). d Tubular atrophy/interstitial fibrosis (T0 vs. T1 + T2). e Severity of cellular or fibrocellular crescent formations (CO vs. C1 vs. C2). $\mathbf{f} J \mathrm{HC}$ (HG I vs. HG II + III). $\mathbf{g}$ Existence of crescents (ISKDC grades I + II vs. III + IV). Only the Oxford E1 lesion ( $p=0.0072)$ was significantly associated with a poor renal survival

Thus, the ISKDC classification, based on the degree of crescent formation, is not useful in adult HSPN.

We also compared renal outcomes in groups defined by the Oxford $\mathrm{C}$ lesion. The $\mathrm{C}$ lesion was added to the Oxford classification in 2016 [16]. Haas et al. reported that cellular and fibrocellular crescents ( $\mathrm{C} 1$ and $\mathrm{C} 2$ lesions) were associated with an increased risk of a poor renal outcome in IgAN patients who did not receive immunosuppressive therapy. Furthermore, the presence of these crescents in over $25 \%$ of glomeruli (C2 lesion) was associated with a poor renal outcome in all patients with IgAN [21]. However, the $\mathrm{C}$ lesion was not significantly associated with poor renal prognosis in our study. We hypothesize that this discrepancy in results occurred because we started immunosuppressive therapy early. In other HSPN studies, the median interval between the onset of purpura and time of renal biopsy was 112 days [13], and the median interval between the kidney biopsy and steroid administration was 9.6 months [26]. In our study, the median interval between the onset of purpura 
Table 4 Univariate and multivariate Cox regression analyses of factors associated with renal outcome

\begin{tabular}{|c|c|c|c|c|c|c|}
\hline Variables & $\begin{array}{l}\text { Univariate model } \\
\text { HR }(95 \% \mathrm{Cl})\end{array}$ & $P$ value & $\begin{array}{l}\text { Multivariate model } 1 \\
\text { HR }(95 \% \mathrm{Cl})\end{array}$ & $P$ value & $\begin{array}{l}\text { Multivariate model } 2 \\
\text { HR }(95 \% \mathrm{Cl})\end{array}$ & $P$ value \\
\hline Age (per 10 years) & $1.64[1.17-2.30]$ & 0.0040 & $1.58[1.15-2.18]$ & 0.0052 & $1.57[1.12-2.21]$ & 0.0095 \\
\hline Sex (male) & $3.04[0.93-9.91]$ & 0.065 & $2.56[0.75-8.73]$ & 0.13 & $2.92[0.74-11.6]$ & 0.13 \\
\hline Diabetes & $1.21[0.16-9.44]$ & 0.85 & & & & \\
\hline Hypertension & $1.30[0.42-3.97]$ & 0.65 & & & & \\
\hline eGFR (per $10 \mathrm{~mL} / \mathrm{min} / 1.73 \mathrm{~m}^{2}$ ) & $0.91[0.73-1.14]$ & 0.41 & & & & \\
\hline mPSL therapy & $1.53[0.47-4.98]$ & 0.48 & & & & \\
\hline Proteinuria ( $\geq 1 \mathrm{~g} /$ day) & $2.16[0.59-7.88]$ & 0.24 & $0.49[0.099-2.43]$ & 0.38 & $0.52[0.11-2.42]$ & 0.41 \\
\hline E1 lesion & $6.13[1.36-27.7]$ & 0.018 & $8.94[1.44-55.7]$ & 0.019 & $6.71[1.06-42.7]$ & 0.044 \\
\hline S1 lesion & $1.58[0.52-4.84]$ & 0.42 & & & & \\
\hline $\mathrm{T} 1$ and 2 lesions & $2.13[0.69-6.52]$ & 0.19 & & & $2.57[0.67-9.77]$ & 0.17 \\
\hline C1 lesion (vs. C0 lesion) & $5.85[0.74-46.2]$ & 0.094 & & & $2.88[0.29-29.1]$ & 0.37 \\
\hline C2 lesion (vs. C0 lesion) & $6.08[0.62-59.3]$ & 0.12 & & & $2.76[0.23-33.2]$ & 0.42 \\
\hline JHC II or III (vs. JHC I) & $1.39[0.46-4.14]$ & 0.56 & & & & \\
\hline ISKDC grade III or IV lesion (vs. grade I or II) & $5.09[0.66-39.1]$ & 0.12 & & & & \\
\hline
\end{tabular}

$H R$ hazard ratio, $\mathrm{Cl}$ confidence interval, eGFR estimated glomerular filtration rate, $\mathrm{mPSL}$ methylprednisolone, $E$ endocapillary proliferation, $S$ segmental sclerosis/ adhesion, $T$ tubular atrophy/interstitial fibrosis, C cellular or fibrocellular crescents, JHC Japanese histologic classification, ISKDC International Study of Kidney Disease in Children

and time of renal biopsy was 53 days, and the median interval between the kidney biopsy and steroid administration was 12 days. As both intervals were much shorter than those in previous studies [13,26], it is possible that Oxford $\mathrm{C}$ lesion was not associated with renal outcome due to this.

We found that JHC was not associated with renal outcome. JHC requires an evaluation of the degree of glomerular histologic changes including cellular, fibrocellular, and fibrous crescents; segmental sclerosis; and global sclerosis [17]. Three facts may explain why JHC was not associated with renal outcome. First, JHC does not include endocapillary proliferation, which was an independent risk factor for poor renal outcome in this study. Second, JHC includes segmental sclerosis and cellular or fibrocellular crescent. In our study, these histological features were not associated with poor renal outcome. Third, JHC was strongly correlated with Oxford T score $(r=0.56)$, which was not an independent predictor for renal outcome in our study. Thus, JHC is unsuitable for the prediction of renal outcome in adults with HSPN.

Our study was limited by its retrospective study design and the limited number of cases. The observed number of renal outcomes in this study yielded a statistical power of approximately $65 \%$ for detecting a HR of 3 at the $5 \%$ significance level in all patients with HSPN. Although HSPN is more frequently observed in Asian countries than in other countries, adult HSPN is rare among kidney diseases. This is because the incidence of adult HSPN is between one-thirtieth to one-half of the incidence of pediatric HSPN [27], and is about one-tenth of the incidence of adult IgAN [22, 28]. Thus, it was difficult to register a sufficient number of adult patients with HSPN for studies. Therefore, prospective and multinational cohort studies are needed.

\section{Conclusions}

In conclusion, endocapillary proliferation was significantly associated with poor renal outcome in adults with HSPN, even in patients receiving immunosuppressive therapy. Other Oxford classification lesions including $\mathrm{C}$ lesions, JHC, and ISKDC classification were not associated with renal outcome.

\section{Additional file}

Additional file 1: Data set of adult HSPN patients (39 females, 35 males, mean age $47.8 \pm 17.4$ years, and all Japanese). (XLSX $12 \mathrm{~kb})$

\section{Abbreviations}

BP: Blood pressure; C: Cellular or fibrocellular crescents; Cl: Confidence interval; CKD: Chronic kidney disease; E: Endocapillary proliferation; eGFR: Estimated glomerular filtration rate; ESKD: End-stage kidney disease; EULAR/PRINTO/PRES: European League Against Rheumatism/Pediatric Rheumatology International Trials Organization/Pediatric Rheumatology European Society; HG: Histologic grade; HR: Hazard ratio; HSP: HenochSchönlein purpura; HSPN: Henoch-Schönlein purpura nephritis; IgAN: IgA nephropathy; IQRs: Interquartile ranges; ISKDC: International study of kidney disease in children; JHC: Japanese Histologic classification; M: Mesangial hypercellularity; S: Segmental sclerosis/adhesion; SD: Standard deviation; T: Tubular atrophy/interstitial fibrosis

\section{Acknowledgements}

We are grateful for the time and efforts of the nephrologists who supported the present study: Dr. Makoto Mizutani, Dr. Yutaka Fujita, Dr. Nobuhide Endo, Dr. Yosuke Saka, Dr. Tomohiko Naruse, Dr. Hirofumi Tamai, Dr. Takatoshi 
Morinaga, Dr. Hideaki Ishikawa, Dr. Takeyuki Hiramatsu, Dr. Takashi Ito, Dr. Arimasa Shirasaki, Dr. Taishi Yamakawa, Dr. Hiroshi Nagaya, Dr. Norimi Ohashi, Dr. Tetsushi Mimura, and Dr. Miho Tatematsu.

\section{Funding}

This study was supported in part by a Grant-in-Aid for Intractable Renal Diseases Research, Research on rare and intractable diseases (H29-Nanchitou (Nan)-Ippan-017), Health and Labour Sciences Research Grants from the Ministry of Health, Labour and Welfare of Japan. This funder had no role in study design, data collection and analysis, decision to publish, or preparation of the manuscript.

\section{Availability of data and materials}

The datasets used and/or analyzed during the current study are available from the corresponding author on reasonable request.

\section{Authors' contributions}

$\mathrm{Kl}, \mathrm{SM}, \mathrm{AH}, \mathrm{TO}, \mathrm{SK}$, and $\mathrm{YY}$ conceived and designed the study. $\mathrm{KI}$ and SM acquired the data. $\mathrm{KI}$ and $\mathrm{ABK}$ evaluated renal biopsy specimens. $\mathrm{KI}$ and MA performed statistical analyses. KI drafted the manuscript. ABK, YY and SM reviewed and edited the manuscript. All the authors have read and approved the final version of the manuscript.

\section{Ethics approval and consent to participate}

This study was conducted in accordance with the principles of Declaration of Helsinki and was approved by the Ethics Committees of Nagoya University Hospital and other thirteen hospitals (approval number: 1135). All participants were informed that their medical records and renal biopsy specimens would be used for the research and signed an informed consent form at the time of kidney biopsy.

\section{Consent for publication}

Not applicable.

\section{Competing interests}

Shoichi Maruyama (Alexion Pharmaceutical Inc., Asahi Kasei Pharma Corporation, Astellas Pharma Inc., Baxter international Inc., Bristol-Myers Squibb, Chugai Pharmaceutical Co., Ltd., Daiichi Sankyo Company, Kyowa Hakko Kirin Co., Ltd., Merck Sharp and Dohme Inc., Mitsubishi Tanabe Pharma Corporation, Mochida Pharmaceutical Co., Ltd., Novartis Pharma K.K., Otsuka Pharmaceutical Co., Ltd., Pfizer Japan Inc., Sanwa Kagaku Kenkyusho Co., Ltd., Sumitomo Dainippon Pharma Co., Ltd., Takeda Pharmaceutical Company Ltd., Teijin Pharma Limited., and Torii Pharmaceutical Co., Ltd.). All other authors have declared no conflicts of interest.

\section{Publisher's Note}

Springer Nature remains neutral with regard to jurisdictional claims in published maps and institutional affiliations.

\section{Author details}

'Department of Nephrology, Nagoya University Graduate School of Medicine, 65 Tsurumai-cho, Showa-ku, Nagoya 466-8550, Japan. ${ }^{2}$ Center for Advanced Medicine and Clinical Research, Nagoya University Hospital, Nagoya, Japan.

\section{Received: 31 March 2018 Accepted: 9 August 2018}

Published online: 17 August 2018

\section{References}

1. Ozen S, Pistorio A, lusan SM, Bakkaloglu A, Herlin T, Brik R, et al. EULAR/ PRINTO/PRES criteria for Henoch-Schönlein purpura, childhood polyarteritis nodosa, childhood Wegener granulomatosis and childhood Takayasu arteritis: Ankara 2008. Part II: final classification criteria. Ann Rheum Dis. 2010; 69:798-806.

2. Kang Y, Park JS, Ha YJ, Kang MI, Park HJ, Lee SW, et al. Differences in clinical manifestations and outcomes between adult and child patients with Henoch-Schönlein purpura. J Korean Med Sci. 2014;29:198-203.

3. Hong S, Ahn SM, Lim DH, Ghang B, Yang WS, Lee SK, et al. Late-onset IgA vasculitis in adult patients exhibits distinct clinical characteristics and outcomes. Clin Exp Rheumatol. 2016;34(3 Suppl 97):S77-83.
4. Kiryluk K, Moldoveanu Z, Sanders JT, Eison TM, Suzuki H, Julian BA, et al. Aberrant glycosylation of lgA1 is inherited in both pediatric lgA nephropathy and Henoch-Schönlein purpura nephritis. Kidney Int. 2011;80: 79-87.

5. Gardner-Medwin JM, Dolezalva P, Cummins C, Southwood TR. Incidence of Henoch-Schönlein purpura, Kawasaki disease, and rare vasculitides in children of different ethnic origins. Lancet. 2002;360:1197-202.

6. O'Shaughnessy MM, Hogan SL, Thompson BD, Coppo R, Fogo AB, Jennette JC. Glomerular disease frequencies by race, sex and region: results from the international kidney biopsy survey. Nephrol Dial Transplant. 2018;33:661-9.

7. Wang P, Tang L, Yao J, Su H, Liu Y, Kong X, et al. The spectrum of biopsyproven secondary glomerular diseases: a cross-sectional study in China. Clin Nephrol. 2017;88:270-6.

8. Okubo Y, Nochioka K, Sakakibara H, Hataya H, Terakawa T, Testa M, et al. Nationwide epidemiological survey of childhood IgA vasculitis associated hospitalization in the USA. Clin Rheumatol. 2016;35:2749-56.

9. Coppo R, Andrulli S, Amore A, Gianoglio B, Conti G, Peruzzi L, et al. Predictors of outcome in Henoch-Schönlein nephritis in children and adults. Am J Kidney Dis. 2006:47:993-1003.

10. Pillebout E, Thervet E, Hill G, Alberti C, Vanhille P, Nochy D. HenochSchönlein purpura in adults: outcome and prognostic factors. J Am Soc Nephrol. 2002;13:1271-8

11. Counahan R, Winterborn MH, White RH, Heaton JM, Meadow SR, Bluett NH, et al. Prognosis of Henoch-Schönlein nephritis in children. Br Med J. 1997;2: $11-4$.

12. Edström Halling S, Söderberg MP, Berg UB. Predictors of outcome in Henoch-Schönlein nephritis. Pediatr Nephrol. 2010;25:1101-8.

13. Kim CH, Lim BJ, Bae YS, Kwon YE, Kim YL, Nam KH, et al. Using the Oxford classification of IgA nephropathy to predict long-term outcomes of Henoch-Schönlein purpura nephritis in adults. Mod Pathol. 2014;27:972-82.

14. Working Group of the International IgA Nephropathy Network and the Renal Pathology Society, Cattran DC, Coppo R, Cook HT, Feehally J, Roberts IS, et al. The Oxford classification of IgA nephropathy: rationale, clinicopathological correlations, and classification. Kidney Int. 2009;76: 534-45.

15. Working Group of the International IgA Nephropathy Network and the Renal Pathology Society, Roberts IS, Cook HT, Troyanov S, Alpers CE, Amore A, et al. The Oxford classification of IgA nephropathy: pathology definitions, correlations, and reproducibility. Kidney Int. 2009;76:546-56.

16. Trimarchi H, Barratt J, Cattran DC, Cook HT, Coppo R, Haas M, et al. Oxford classification of IgA nephropathy 2016: an update from the $\lg A$ nephropathy classification working group. Kidney Int. 2017;91:1014-21.

17. Kawamura T, Joh K, Okonogi H, Koike K, Utsunomiya Y, Miyazaki Y, et al. A histologic classification of IgA nephropathy for predicting long-term prognosis: emphasis on end-stage renal disease. J Nephrol. 2013;26:350-7.

18. Sato R, Joh K, Komatsuda A, Ohtani H, Okuyama S, Togashi M, et al. Validation of the Japanese histologic classification 2013 of immunoglobulin a nephropathy for prediction of long-term prognosis in a Japanese singlecenter cohort. Clin Exp Nephrol. 2015;19:411-8.

19. Kaihan AB, Yasuda Y, Katsuno T, Kato S, Imaizumi T, Ozeki T, et al. The Japanese histologic classification and T-score in the Oxford classification system could predict renal outcome in Japanese IgA nephropathy patients. Clin Exp Nephrol. 2017:21:986-94.

20. Matsuo S, Imai E, Horio M, Yasuda Y, Tomita K, Nitta K, et al. Collaborators developing the Japanese equation for estimated GFR. Revised equations for estimated GFR from serum creatinine in Japan. Am J Kidney Dis. 2009;53: 982-92.

21. Haas M, Verhave JC, Liu ZH, Alpers CE, Barratt J, Becker JU, et al. A multicenter study of the predictive value of crescents in IgA nephropathy. J Am Soc Nephrol. 2017;28:691-701.

22. Kanda Y. Investigation of the freely available easy-to-use soft-ware 'EZR' for medical statics. Bone Marrow Transplant. 2013;48:452-8.

23. Chakera A, MacEwen C, Bellur SS, Chompuk LO, Lunn D, Roberts ISD. Prognostic value of endocapillary hypercellularity in IgA nephropathy patients with no immunosuppression. J Nephrol. 2016;29:367-75.

24. Coppo R, Troyanov S, Bellur S, Cattran D, Cook HT, Feehally J, et al. Validation of the Oxford classification of IgA nephropathy in cohorts with different presentations and treatments. Kidney Int. 2014;86:828-36.

25. Lv J, Shi S, Xu D, Zhang H, Troyanov S, Cattran DC, et al. Evaluation of the Oxford classification of IgA nephropathy: a systematic review and metaanalysis. Am J Kidney Dis. 2013;62:891-9. 
26. Oh HJ, Ahn SV, Yoo DE, Kim SJ, Shin DH, Lee MJ, et al. Clinical outcomes, when matched at presentation, do not vary between adult-onset Henöch-Schönlein purpura nephritis and IgA nephropathy. Kidney Int. 2012:82:1304-12.

27. Piram M, Mahr A. Epidemiology of immunoglobulin a vasculitis (Henoch-Schönlein): current state of knowledge. Curr Opin Rheumatol. 2013;25:171-8.

28. Komatsu H, Fujimoto S, Yoshikawa N, Kitamura H, Sugiyama $H$, Yokoyama $H$. Clinical manifestations of Henoch-Scho"nlein purpura nephritis and IgA nephropathy: comparative analysis of data from the Japan renal biopsy registry (J-RBR). Clin Exp Nephrol. 2016;20:552-60.

- fast, convenient online submission

- thorough peer review by experienced researchers in your field

- rapid publication on acceptance

- support for research data, including large and complex data types

- gold Open Access which fosters wider collaboration and increased citations

- maximum visibility for your research: over $100 \mathrm{M}$ website views per year

At BMC, research is always in progress.

Learn more biomedcentral.com/submissions 